\title{
A Blue Native-PAGE analysis of membrane protein complexes in Clostridium thermocellum
}

\author{
Yanfeng Peng ${ }^{1}$, Yuanming Luo ${ }^{1}$, Tingting $\mathrm{Yu}^{1}$, Xinping $\mathrm{Xu}^{1,2}$, Keqiang Fan ${ }^{1}$, Youbao Zhao ${ }^{1}$, Keqian Yang ${ }^{1 *}$
}

\begin{abstract}
Background: Clostridium thermocellum is a Gram-positive thermophilic anaerobic bacterium with the unusual capacity to convert cellulosic biomass into ethanol and hydrogen. Identification and characterization of protein complexes in C. thermocellum are important toward understanding its metabolism and physiology.

Results: A two dimensional blue native/SDS-PAGE procedure was developed to separate membrane protein complexes of $C$. thermocellum. Proteins spots were identified by MALDI-TOF/TOF Mass spectrometry. 24 proteins were identified representing 13 distinct protein complexes, including several putative intact complexes. Interestingly, subunits of both the F1-F0-ATP synthase and the V1-V0-ATP synthase were detected in the membrane sample, indicating C. thermocellum may use alternative mechanisms for ATP generation.

Conclusion: Two dimensional blue native/SDS-PAGE was used to detect membrane protein complexes in C. thermocellum. More than a dozen putative protein complexes were identified, revealing the simultaneous expression of two sets of ATP synthase. The protocol developed in this work paves the way for further functional characterization of these protein complexes.
\end{abstract}

\section{Background}

Clostridium thermocellum is a Gram-positive thermophilic anaerobe capable of degrading cellulose and producing ethanol and hydrogen. These qualities render $C$. thermocellum potentially useful for the production of biofuel from biomass. The cellulytic activities of this organism were well studied, the corresponding enzymes were found to organize into a cell surfaced bound multienzyme complex, termed cellulosome [1]. The arrangement of the enzymatic subunits in the cellulosome complex, made possible by a scaffoldin subunit, promotes enhanced substrate binding and degradation. However, other parts of its cellular functions are not well understood. Recently, a genome scale metabolic model was constructed [2], which provides a good basis for the overall understanding of its metabolism. Since membrane is where many important physiological functions, such as energy generation, protein trafficking, and small molecule transport [3], take place, we focused on membrane protein complexes as a start point to identify

\footnotetext{
* Correspondence: yangkq@im.ac.cn

'State Key Laboratory of Microbial Resources, Institute of Microbiology,

Chinese Academy of Sciences, Beijing 100101, PR China

Full list of author information is available at the end of the article
}

unique features of C. thermocellum. Identification of protein complexes in C. thermocellum is an important step toward understanding cellular behavior at an integrative level.

Blue native-PAGE (BN-PAGE) is a charge shift method first developed by Schägger and von Jagow [4] to separate membrane protein complexes. It has been used successfully to characterize respiratory complexes in yeast mitochondria and Paracoccus denitrificans [5,6], photosynthetic complexes in plants and Synechocystis $[7,8]$, and cell envelope protein complexes in E. coli $[9,10]$. It differs from other native gel electrophoresis mainly because the electrophoretic mobility of a protein is determined by the negative charge of the bound Coomassie blue dye, while separation of proteins is achieved by the molecular sieve effect provided by the polyacrylamide gradient of descending pore size similar to other PAGE methods. BN-PAGE, when coupled with a second dimensional SDS-PAGE and mass spectrometry offers an attractive proteomic solution for analysis of membrane protein complexes and for basic expression profiling. It can complement traditional two-dimensional gel electrophoresis proteomic method by providing a platform to separate membrane proteins.
Ciomed Central

(c) 2011 Peng et al; licensee BioMed Central Ltd. This is an Open Access article distributed under the terms of the Creative Commons Attribution License (http://creativecommons.org/licenses/by/2.0), which permits unrestricted use, distribution, and reproduction in any medium, provided the original work is properly cited. 
In this work, we developed a BN-PAGE protocol for the analysis of membrane protein complexes of $C$. thermocellum.

\section{Results and Discussion}

\section{Preparation of Membrane Protein Samples}

Purification of protein complexes in an intact form (i.e. complete with all peripherally associated proteins) is largely dependent on the solubilization conditions used and can differ for various complexes. By testing four commonly used detergents at different concentrations (see "Methods"), we were able to select a protocol using the detergent $\mathrm{n}$-dodecyl-D-maltoside (DDM). This protocol detected a number of complexes in the molecular mass range from 60 to over 1,000 $\mathrm{kDa}$. The molecular mass of protein complexes was calculated by plotting the MWs of marker proteins against their migration distances.
To identify the individual proteins in each complex, the one-dimensional $\mathrm{BN}$ gel strips were analyzed in the second dimension by SDS-PAGE, Figure 1. Putative complexes were consequently resolved into vertical "channels" enabling visualization of the individual constituents. Proteins that had formed a complex in the BN gel were tentatively recognized by their locations on a vertical line on the SDS gel, and also by their similar shapes on the SDS gel (as a result of co-migration in the $\mathrm{BN}$ gel).

\section{Protein Identification}

Thirty six spots were picked from the SDS gel for MALDI-TOF/TOF identification. Thirty proteins were identified in 28 spots (Figure 1), and they represent 24 different proteins (Table 1). Among them, 9 proteins were predicted by TMHMM $[11,12]$ (transmembrane hidden Markov model, http://www.cbs.dtu.dk/services/

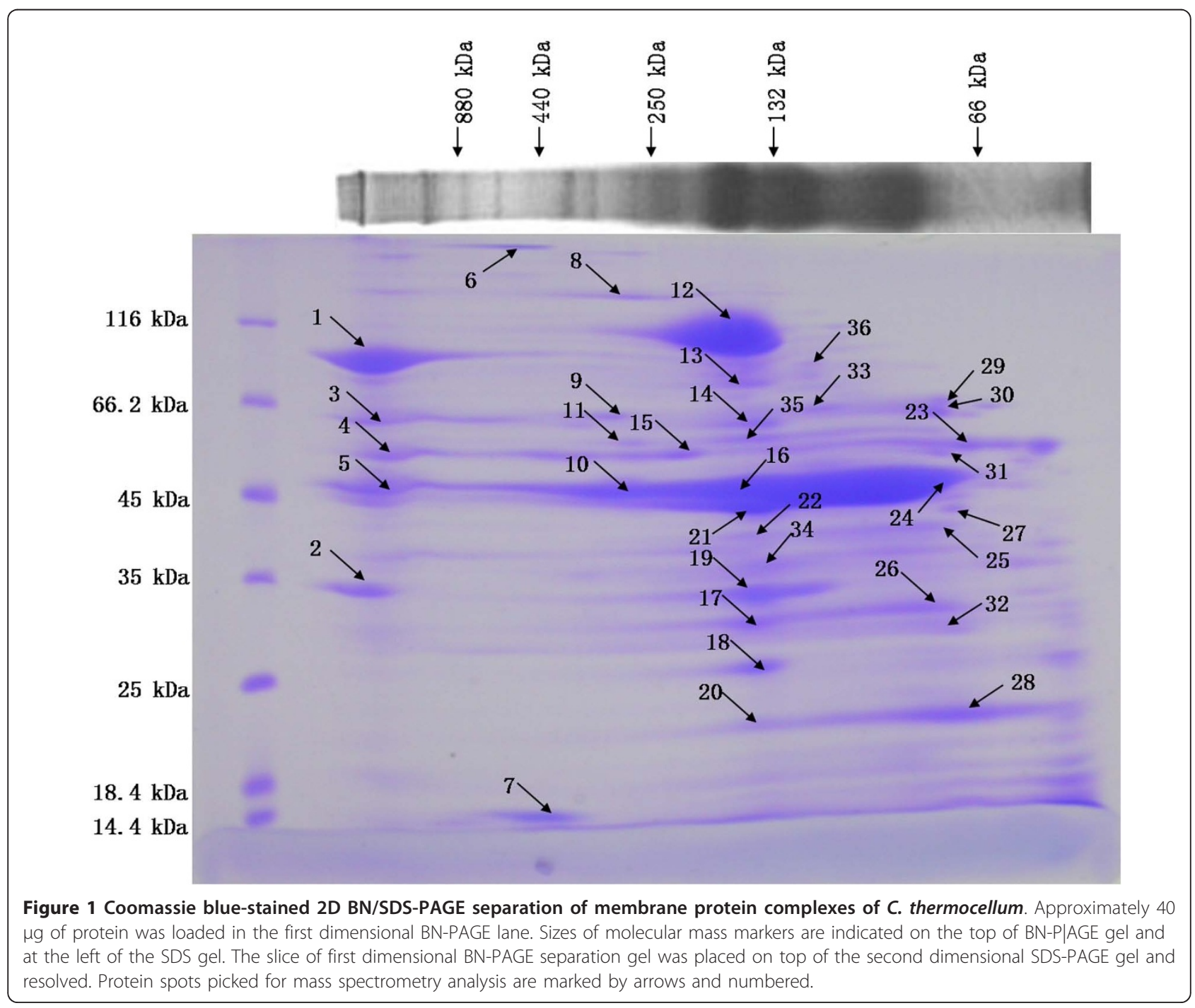


Table 1 Putative membrane proteins of $C$. thermocellum identified by mass spectrometry

\begin{tabular}{|c|c|c|c|c|c|c|c|c|}
\hline $\begin{array}{l}\text { Spots } \\
\text { Id }^{a} \\
\end{array}$ & $\begin{array}{l}\text { Gene } \\
\text { locus }\end{array}$ & $\begin{array}{l}\text { NCBI accession } \\
\text { number/gi }\end{array}$ & Protein descriptions $^{b}$ & $\mathrm{Mr}^{\mathrm{c}}$ & $\begin{array}{l}\text { MASCOT } \\
\text { Score }\end{array}$ & $\begin{array}{l}\text { Peptides } \\
\text { matched }\end{array}$ & $\begin{array}{c}\text { Sequence } \\
\text { Coverage (\%) }\end{array}$ & $\begin{array}{c}\text { TMHMM } \\
\text { prediction }\end{array}$ \\
\hline 1 & Cthe_0423 & 125972944 & $\begin{array}{l}\text { bifunctional acetaldehyde/alcohol } \\
\text { dehydrogenase }\end{array}$ & 95992.3 & 427 & 46 & 39 & \\
\hline 2 & Cthe_0858 & 125713600 & hypothetical protein & 35296.4 & 411 & 26 & 58 & 1 \\
\hline 3 & Cthe_2253 & 125974738 & ATP-dependent metalloprotease FtsH & 66652.9 & 253 & 34 & 45 & 2 \\
\hline 4 & Cthe_0699 & 125713442 & carboxyl transferase & 56037.9 & 700 & 39 & 49 & \\
\hline 5 & Cthe_1020 & 125973535 & solute-binding protein & 49976.2 & 164 & 28 & 45 & \\
\hline 6 & Cthe_0016 & 125972541 & Ferritin and Dps & 18602.9 & 61 & 9 & 42 & \\
\hline 7 & Cthe_0016 & 125972541 & Ferritin and Dps & 18602.9 & 189 & 14 & 42 & \\
\hline 8 & Cthe_2693 & 125975175 & hypothetical protein & 17817.5 & 74 & 12 & 26 & 1 \\
\hline 9 & Cthe_2267 & 125714977 & V-type ATP synthase subunit A & 65320 & 214 & 32 & 33 & \\
\hline 10 & Cthe_1020 & 125973535 & solute-binding protein & 49976.2 & 199 & 25 & 44 & \\
\hline 10 & Cthe_2268 & 125714978 & V-type ATP synthase beta chain & 50714.2 & 109 & 26 & 43 & \\
\hline 10 & Cthe_2608 & 125975091 & ATP synthase $F 1$, beta subunit & 51000 & 87 & 22 & 38 & \\
\hline 11 & Cthe_2606 & 125975089 & ATP synthase F1, alpha subunit & 55810 & 307 & 22 & 33 & \\
\hline 12 & Cthe_2348 & 125715058 & S-layer-like region; Ig-related & 113309.3 & 550 & 42 & 34 & 1 \\
\hline 13 & Cthe_0418 & 125972939 & $\begin{array}{l}\text { polynucleotide phosphorylase/ } \\
\text { polyadenylase }\end{array}$ & 77304 & 84 & 17 & 26 & \\
\hline 14 & Cthe_3148 & 125975626 & $A B C$ transporter related protein & 70461.1 & 95 & 12 & 16 & 5 \\
\hline 15 & Cthe_0699 & 125973217 & carboxyl transferase & 56037.9 & 148 & 25 & 38 & \\
\hline 16 & Cthe_1020 & 125973535 & solute-binding protein & 49976.2 & 486 & 33 & 48 & \\
\hline 17 & Cthe_1557 & 125974066 & $\begin{array}{l}\text { ABC transporter related protein ATP- } \\
\text { binding protein }\end{array}$ & 30203.7 & 175 & 21 & 47 & \\
\hline 18 & Cthe_1018 & 125973533 & $\begin{array}{l}\text { binding-protein-dependent transport } \\
\text { systems inner membrane component }\end{array}$ & 31919.9 & 67 & 13 & 23 & 6 \\
\hline 19 & Cthe_1840 & 125974344 & cysteine synthase & 33392 & 469 & 25 & 57 & \\
\hline 20 & Cthe_1104 & 125713844 & prepilin-type cleavage/methylation & 19233.2 & 183 & 21 & 65 & \\
\hline 21 & Cthe_1862 & 125974366 & $A B C$ transporter related protein & 42056.4 & 317 & 31 & 38 & \\
\hline 22 & Cthe_1754 & 125714483 & solute-binding protein & 35734.5 & 143 & 19 & 48 & 1 \\
\hline 23 & Cthe_2709 & 125975191 & hypothetical protein & 55140 & 95 & 14 & 19 & \\
\hline 24 & Cthe_1020 & 125973535 & solute-binding protein & 49976.2 & 385 & 32 & 47 & \\
\hline 25 & Cthe_1754 & 125714483 & solute-binding protein & 35734.5 & 241 & 29 & 64 & 1 \\
\hline 26 & Cthe_1555 & 125974064 & $\begin{array}{l}\text { ABC-type metal ion transport system } \\
\text { periplasmic component }\end{array}$ & 32242.5 & 73 & 12 & 32 & 1 \\
\hline 27 & Cthe_1869 & 125714598 & ornithine carbamoyltransferase & 34235.9 & 304 & 20 & 47 & \\
\hline 28 & Cthe_1104 & 125713844 & prepilin-type cleavage/methylation & 19233.2 & 539 & 21 & 68 & \\
\hline
\end{tabular}

Note:

${ }^{a}$ Spots identification numbers (Spots ID) correspond to the numbers in Figure 1.

${ }^{b}$ Protein annotations are based on the genome annotation of $C$. thermocellum ATCC 27405.

${ }^{c} \mathrm{Mr}$, molecular mass.

TMHMM/) to be membrane protein containing $\alpha$-helical transmembrane segments. The rest maybe membraneassociated proteins (described below). Many atypical membrane proteins are tethered to the membranes through lipid moieties, hydrophobic patches, charge interactions or by their association with a membrane protein complexes. The identified proteins were organized into functional groups based on COG using COGnitor tool available at NCBI $[13,14]$ and transporter related proteins were organized in membrane transporter complexes. Putative protein complexes and their estimated sizes observed on the BN-PAGE were summarized in
Table 2. The false positive rate of protein identification was calculated by reverse database search to be lower than $2.5 \%$.

\section{Complexes in energy production and conversion}

In prokaryotes, three evolutionarily related sub types of ATPases/synthases were found, categorized as $F-\left(F_{1}-F_{0^{-}}\right)$, $\mathrm{V}-\left(\mathrm{V}_{1}-\mathrm{V}_{0}\right)$ and A- $\left(\mathrm{A}_{1}-\mathrm{A}_{0}\right)$ type ATPases on the basis of their function and taxonomic origins. Although eukaryotes contain both F- and V-ATPases, each highly specialized in its physiological functions; archaea and eubacteria typically contain only one subtype of ATPase [15]. 
Table 2 Putative membrane protein complexes of C. thermocellum

\begin{tabular}{|c|c|c|c|c|}
\hline Complex & Spots Id ${ }^{d}$ & Gene locus & Protein descriptions ${ }^{e}$ & Approximate mass ${ }^{f}(\mathrm{kDa})$ \\
\hline \multirow[t]{2}{*}{$\mathrm{C} 1$} & 9 & Cthe_2267 & V-type ATP synthase subunit A & 300 \\
\hline & 10 & Cthe_2268 & V-type ATP synthase beta chain & \\
\hline \multirow[t]{2}{*}{$\mathrm{C} 2$} & 10 & Cthe_2608 & ATP synthase F1, beta subunit & 300 \\
\hline & 11 & Cthe_2606 & ATP synthase F1, alpha subunit & \\
\hline C3 & 1 & Cthe_0423 & bifunctional acetaldehyde/alcohol dehydrogenase & $>880$ \\
\hline C4 & 15 & Cthe_0699 & carboxyl transferase & 220 \\
\hline C5 & 19 & Cthe_1840 & cysteine synthase & 130 \\
\hline C6 & 27 & Cthe_1869 & ornithine carbamoyltransferase & 100 \\
\hline$C 7$ & 3 & Cthe_2253 & ATP-dependent metalloprotease FtsH & $>880$ \\
\hline $\mathrm{C} 8$ & 13 & Cthe_0418 & polynucleotide phosphorylase/polyadenylase & 150 \\
\hline C9 & 7 & Cthe_0016 & Ferritin and Dps & 440 \\
\hline $\mathrm{C} 10$ & 14 & Cthe_3148 & $A B C$ transporter related protein & 140 \\
\hline \multirow[t]{3}{*}{$\mathrm{C} 11$} & 16 & Cthe_1020 & solute-binding protein & 190 \\
\hline & 18 & Cthe_1018 & binding-protein-dependent transport systems inner membrane component & \\
\hline & 21 & Cthe_1862 & $A B C$ transporter related protein & \\
\hline $\mathrm{C} 12$ & 17 & Cthe_1557 & ABC transporter related protein ATP-binding protein & 140 \\
\hline $\mathrm{C} 13$ & 22 & Cthe_1754 & solute-binding protein & 170 \\
\hline C14 & 12 & Cthe_2348 & S-layer-like region; Ig-related & 140 \\
\hline C15 & 20 & Cthe_1104 & prepilin-type cleavage/methylation & $20 \sim 180$ \\
\hline
\end{tabular}

Most eubacteria contain F-ATPases, but some eubacteria contain both F- and V-ATPases, whereas all known archaea contain complexes that are evolutionarily closer to $\mathrm{V}$-ATPases and are referred to as A-ATPases due to their archael origin.

Generally, the $\mathrm{F}_{1}-\mathrm{F}_{0}$-ATP synthase contains eight subunits arranged in two subcomplexes: $F_{1}\left(\alpha_{3}, \beta_{3}, \gamma, \delta\right.$, $\varepsilon)$ and $F_{0}\left(a, b_{2}, c_{10-14}\right)$ [16]. The $V_{1}-V_{0}$-ATP synthase contains nine subunits arranged in two subcomplexes: $\mathrm{V}_{1}\left(\mathrm{~A}_{3}, \mathrm{~B}_{3}, \mathrm{D}, \mathrm{F}\right)$ and $\mathrm{V}_{0}(\mathrm{G}, \mathrm{E}, \mathrm{C}, \mathrm{I}, \mathrm{L})$ [17]. Interestingly, in the genome of $C$. thermocellum, there are two ATPase gene clusters: a $F_{1}-F_{0}$-ATP synthase (Cthe_2602-Cthe_2609) and $\mathrm{V}_{1}-\mathrm{V}_{0}$-ATP synthase (Cthe_2261-Cthe_2269), both with a complete set of subunits.

We detected two subunits of $\mathrm{F}_{1}-\mathrm{F}_{0}$-ATPase, $\mathrm{F}_{1}$ subunit $\alpha$ (Cthe_2606, $55.8 \mathrm{kDa}$ ) and $\mathrm{F}_{1}$ subunit $\beta$ (Cthe_2608, $51 \mathrm{kDa}$ ), with an estimated molecular mass of $300 \mathrm{kDa}$ and two subunits of $V_{1}-V_{0}$-ATPase, $V_{1}$ subunit $A$ (Cthe_2267, $65 \mathrm{kDa}$ ) and $\mathrm{V}_{1}$ subunit B (Cthe_2268, 50 $\mathrm{kDa}$ ), with an estimated molecular mass of $300 \mathrm{kDa}$. These may represent a subcomplex of $\alpha_{3} \beta_{3}$ and $A_{3} B_{3}$ in $\mathrm{F} 1$ and $\mathrm{V}_{1}$, respectively. We conducted a large scale search of ATPase in published genomes of eubacteria from NCBI, 700 genomes were found to contain genes encoding F-type ATPases, 93 genomes contain genes encoding V-type ATPases, and only 44 genomes contain both F-type and V-type ATPases (see Additional file 1).
The co-presence of both ATPases in a bacterium is limited to a few genera, which include several Streptococcus, Clostridium, Anaeromyxobacter strains, two Cyanothece species, an Enterococcus faecalis and a Nitrosococcus oceani. We deduce these may reflect unusual ATP generating mechanisms in these bacteria. In this work, we found that both the F- and V-type ATPases are expressed C. themocellum. Co-presence of V- and Ftype ATPases in a bacterium is uncommon. Previously, only Enterococcus hirae was reported to utilize both types of ATPases [18]. The E. hirae V-type ATPase differs from typical V-type ATPase in preferentially transporting $\mathrm{Na}^{+}[19,20]$ instead of $\mathrm{H}^{+}$. In the thermophilic Clostridium fervidus, a second example of $\mathrm{Na}^{+}$-pumping $\mathrm{V}$-type ATPase was reported [21]. It is reasonable to speculate that the V-type ATPase in C. thermocellum is a $\mathrm{Na}^{+}$-pumping ATPase. Most bacteria contain either Ftype or V-type ATPase, among those that contain both types of ATPases, new functional variants of ATPases could be identified and their roles in bacterial physiology could be investigated.

Bifunctional acetaldehyde/alcohol dehydrogenase (ALDH-ADH, Cthe_0423, $96 \mathrm{kDa}$ ) was detected at over $880 \mathrm{kDa}$. ADHs could be classified into 3 classes based on their length: short chain ADH (approximately 250 residues) and medium chain $\mathrm{ADH}$ (approximately 370 residues) exist in a homotetramer form [22], but a structure of long chain ADH (over 380 amino acids and 
often as many as 900 amino acid residues) was not reported. The ALDH-ADH of C. thermocellum appears to be a long chain $\mathrm{ADH}$ and forms a homo-multimer like the ADH in Entamoeba histolytica [23]. Alcohol dehydrogenases were reported to be membrane-bound protein complexes [24-26], it is reasonable to observe $\mathrm{ADH}$ in $C$. thermocellum membrane fraction.

\section{Complexes in lipid transport and metabolism}

Carboxyl transferase (CT, Cthe_0699, 56 kDa) was identified at $\sim 220 \mathrm{kDa}$. In eubacteria, CT is part of acetyl coenzyme A carboxylase (ACC) complex, which normally consists of biotin carboxylase (BC), biotin carboxyl carrier protein (BCCP), and CT. Typically, CT contains two subunits in a stable $\alpha_{2} \beta_{2}$ form $[27,28]$. But, in Streptomyces coelicolor, the ACC enzyme has a subunit (590 residues) with fused $\mathrm{BC}$ and $\mathrm{BCCP}$ domains, and another subunit (530 residues) that contains the fused CT domains [29]. In archaea, ACC is a multi-subunit enzyme, with BC, BCCP and CT subunits. The archael $\mathrm{CT}$ subunit is also a single protein (520 residues) in a $\mathrm{CT}_{4}$ form, rather than two separate subunits, which is similar to the $\beta$ subunit (CT) of the ACC from Streptomyces [30]. In C. thermocellum, CT is a $56 \mathrm{kDa}$ protein, which contains two domains of carboxyl transferase, and we did not detect other ACC subunits on BN/SDSPAGE. So the CT appears to be a sub complex of $\mathrm{CT}_{4}$ not associated with BC and BCCP. CT was also detected at over $880 \mathrm{kDa}$, which maybe due to precipitation during electrophoresis or CT formed a large complex with other subunits of ACC. Previous studies also suggested ACC may form a membrane-associated protein complex $[31,32]$.

\section{Complexes in amino acid transport and metabolism}

Serine-Acetyl-Transferase (SAT, Cthe_1840, 33.4 kDa), a subunit of cysteine synthase (CS), was detected at $\sim 130$ $\mathrm{kDa}$ corresponding to the size of intact CS complex. Typical CS complex is composed of one SAT and two O-Acetyl-Serine-(Thiol)-Lyases (OAS-TL, Cthe_1842, $46.5 \mathrm{kDa}$ ) [33,34], but we did not detect OAS-TL. It is likely that OAS-TL was masked by the very abundant protein, Cthe_1020. Detection of CS in the membrane fractions has been reported in other studies $[9,35]$.

Ornithine carbamoyltransferase (OTCase, Cthe_1869, $34 \mathrm{kDa}$ ) was identified at $\sim 100 \mathrm{kDa}$, probably in a typical homo-trimer form [36-39]. Some studies suggest that OTCase is a cell surface protein $[40,41]$ whereas Shi et al. [42] reported that OTCase maybe a membrane-associated protein based on sequence analyses. Our results support the membrane location of OTCase.

ATP-dependent metalloprotease FtsH (Cthe_2253, $66.6 \mathrm{kDa}$ ) was detected at over $880 \mathrm{kDa}$. FtsH is a cytoplasmic membrane-integrated protein that functions to processively degrade both cytoplasmic and membrane proteins in concert with protein unfolding and is known to form a large membrane-spanning holoenzyme of more than $1000 \mathrm{kDa}$ with the prohibitin-like proteins HflK and HflC [43] or in a hexameric ring structure $[44,45]$. Although HflK and HflC homologues were not detected from the gel, our results indicate that FtsH forms a large complex on the membrane.

\section{Complexes in translation, ribosomal structure and biogenesis}

Polyribonucleotide phosphorylase (PNPase, Cthe_0418, $77 \mathrm{kDa}$ ) was identified at $\sim 150 \mathrm{kDa}$ in the gel at a size of a dimer. It was reported to form a homo-trimer in eukaryotes, bacteria, and archaea [46-50] and was found in membrane fractions $[51,52]$.

\section{Complexes in inorganic ion transport and metabolism}

We detected ferritin (Cthe_0016, $18.6 \mathrm{kDa}$ ) at $440 \mathrm{kDa}$, indicating that it is intact in a typical 24 mer form on BN-PAGE [53,54]. But ferritin was also detected at over $110 \mathrm{kDa}$ on SDS-PAGE, maybe due to incomplete denaturation. Ferritin is a well known membrane-bound protein.

\section{Membrane Transport Complexes}

Three solute binding proteins (BP, Cthe_1020, Cthe_1555, Cthe_1754), two ATP binding cassette proteins (ABC, Cthe_1557, Cthe_1862), one integral membrane component (IM, Cthe_1018), and an ABC transporter (Cthe_3148) with fused ABC and IM domains were identified from the SDS gel.

$A B C$ transporter diverged into three main classes: Class 1 is comprised of fused ABC and IM domains; Class 2 is comprised of two tandem repeated $A B C$ domains with no IM domains, this class likely does not function as transporters; Class 3 contains independent $\mathrm{IM}$ and $\mathrm{ABC}$ domains, that correspond to most BPdependent importers[55]. A typical class 3 ABC transporter complex consists of one BP, two $\mathrm{ABCs}$ and two IMs, but the interactions of BP with the complex are weak, so most often only ABC and IM were isolated in a transporter complex $[56,57]$. In Gram-positive bacteria, BP is either tethered to the cell surface via an Nterminal Cys residue covalently attached to the lipid membrane or by interaction with the IM component of a transporter complex [55].

An ABC transporter (Cthe_3148, $70 \mathrm{kDa}$ ) was detected at $\sim 140 \mathrm{kDa}$, it is a Class $1 \mathrm{ABC}$ transporter with fused $A B C$ and IM domains. The estimated size of Cthe_3148 indicates that it was isolated in an intact dimeric form.

The solute binding protein (Cthe_1020, $49 \mathrm{kDa}$ ), the integral membrane protein (Cthe_1018, $32 \mathrm{kDa}$ ) and the 
ATP binding cassette protein (Cthe_1862, $42 \mathrm{kDa}$ ) were identified on a vertical line at $\sim 190 \mathrm{kDa}$. In the genome of $C$. thermocellum, no ATP binding cassette proteins are found near Cthe_1020 and Cthe_1018, and Cthe_1862 is not adjacent to other BP or IM proteins. The identification of these proteins on a vertical line strongly suggests that they form a transporter complex. Cthe_1020 is an abundantly expressed protein under our culture condition, it was detected at $\sim 100 \mathrm{kDa}$ to over $880 \mathrm{kDa}$, and the high molecular weight spots maybe result of protein precipitation during electrophoresis.

Cthe_1555, Cthe_1556 and Cthe_1557 form an ABC transporter gene cluster in the genome. The ATP binding cassette protein (Cthe_1557, $30 \mathrm{kDa}$ ) was detected at an estimated molecular mass of $\sim 140 \mathrm{kDa}$. But the integral membrane protein Cthe_1556 (26 kDa) and solute binding protein Cthe_1555 (32 kDa) were not detected. The estimated size of this $\mathrm{ABC}$ transporter complex suggests it contains two subunits of Cthe_1557, two subunits Cthe_1556 and one subunit of Cthe_1555 as an intact complex. Cthe_1555 was detected at $~ 100$ $\mathrm{kDa}$ on a horizontal line with Cthe_1557, which could be due to dissociation of the transporter complex during electrophoresis.

Cthe_1752, Cthe_1753 and Cthe_1754 form an ABC transporter gene cluster in the genome. The solute binding protein (Cthe_1754, $36 \mathrm{kDa}$ ) was detected at $\sim 170$ $\mathrm{kDa}$. But the integral membrane protein Cthe_1753 (37 $\mathrm{kDa}$ ) and ATP binding cassette protein Cthe_1752 (30 $\mathrm{kDa}$ ) was not detected. The size of $\mathrm{ABC}$ transporter complex estimated by BN-PAGE, suggests it contains two subunits Cthe_1752, two subunits Cthe_1753 and one subunit of Cthe_1754.

In this study, we did not detect the proteins in other ABC transporter gene clusters studied in vitro by Nataf [58] except Cthe_1020.

\section{Other protein complexes}

In Gram-positive bacteria, S-layer proteins are known to non-covalently attach to the pyruvylated negativelycharged secondary cell wall polymers (SCWP) by the surface layer homology (SLH) domains [59-61]. We detected S-layer protein (Cthe_2348, $113 \mathrm{kDa}$ ) at $\sim 140$ $\mathrm{kDa}$, probably in a monomeric form, and there maybe a fragment of SCWP tethered with S-layer protein.

Prepilin (Cthe_1104, $19 \mathrm{kDa}$ ) was identified from 20 $\mathrm{kDa}$ to $180 \mathrm{kDa}$ in the SDS gel, this may reflect that the prepilins were in a process of pilin assembly [62].

\section{Hypothetical proteins}

Three hypothetical proteins (Cthe_0858, Cthe_2693 and Cthe_2709) were detected in our membrane sample. Although Cthe_0858 showed weak similarity to domains designated PRK 13665, pfam 12127 and COG4864. The functions of these domains or their corresponding proteins are not known.

\section{Discussions on the method}

Previously, a Bicine-dSDS-PAGE method was developed to separate membrane proteins [63], it employs strong solubilization conditions in both dimensions of SDSPAGE. The method is suitable for membrane proteomics study, and was used to identify 81 membrane proteins from C. thermocellum [64]. In this work, BN/SDS-PAGE was applied in the analysis of membrane protein complexes of $C$. thermocellum for the first time. Although the first dimensional BN-PAGE was carefully optimized, the second dimensional SDS-PAGE proved difficult to perform probably because the solubilization factors were altered during SDS electrophoresis. So technically, it is still a huge challenge to isolate and solubilize membrane protein complexes as well as to separate these complexes on BN/SDS-PAGE. To isolate intact protein complexes, gentle cell disruption method must be considered. We used sonication conditions (with low sonication power and long sonication intervals), that sufficiently protected complex stability. After repeat optimization of various conditions, we were able to solubilize and separate a subfraction of membrane protein complexes and to identify 24 membranes proteins representing 13 intact or sub protein complexes. Most of the proteins identified were previously reported to be membrane proteins, thus validating our sample preparation protocol. Many protein complexes we reported were identified for the first time in C. thermocellum, thus our findings and protocol paved the way for future detailed characterization of these complexes. BN/SDS-PAGE is a suitable approach for large scale protein-protein interaction investigation, and it is probably the only method of choice to analyze membrane protein complexes on proteomic scale. This method allowed us to detect the simultaneous expression of two sets of ATP synthases (V-and F-type ATPases) in C. thermocellum, and this finding provides strong bases for the future investigation into the distinct roles of these ATPases in this bacterium.

\section{Conclusions}

Two dimensional blue native/SDS-PAGE was used to detect membrane protein complexes in C. thermocellum and revealed the simultaneous expression of two sets of ATP synthases. The protocol developed in this work paves the way for further functional characterization of membrane protein complexes in this bacterium.

\section{Methods}

Bacterial strains and growth conditions

C. thermocellum DSM 1237 (ATCC 27405) was obtained from Deutsche Sammlung von Mikroorganismen und 
Zellkulturen. It was cultured at $60^{\circ} \mathrm{C}$ in a medium containing: (NH4) ${ }_{2} \mathrm{SO}_{4} 1.30 \mathrm{~g}, \mathrm{MgCl}_{2} \cdot 6 \mathrm{H}_{2} \mathrm{O}, 2.60 \mathrm{~g}, \mathrm{KH}_{2} \mathrm{PO}_{4}$ $1.43 \mathrm{~g}, \mathrm{~K}_{2} \mathrm{HPO}_{4} \cdot 3 \mathrm{H}_{2} \mathrm{O} 7.20 \mathrm{~g}, \mathrm{CaCl}_{2} \cdot 2 \mathrm{H}_{2} \mathrm{O} 0.13 \mathrm{~g}$, $\mathrm{Na}-\beta$-glycerophosphate $6.00 \mathrm{~g}, \mathrm{FeSO}_{4} \cdot 7 \mathrm{H}_{2} \mathrm{O} 1.10 \mathrm{mg}$, Glutathione $0.25 \mathrm{~g}$, Yeast Extract $4.50 \mathrm{~g}$, Resazurin $1.00 \mathrm{mg}$, Cellobiose $5.00 \mathrm{~g}$ per litre water. The basal medium was adjusted to $\mathrm{pH} 7.2$ with $10 \% \mathrm{NaOH}$ and the headspace of the medium container was continuously flushed with oxygen-free nitrogen. All chemicals were purchased from Sigma-Aldrich (St. Louis, MO, USA) unless otherwise noted.

\section{Preparation of crude membrane protein fraction}

C. thermocellum cells were harvested at late log phase by centrifugation at $8000 \mathrm{~g}$ for $10 \mathrm{~min}$ at $4^{\circ} \mathrm{C}$, washed twice with $50 \mathrm{mM}$ Tris- $\mathrm{HCl}(\mathrm{pH} \mathrm{7.5)}$, and then resuspended in $50 \mathrm{mM}$ Tris- $\mathrm{HCl}(\mathrm{pH} 7.5)$ containing 0.5 mM PMSF (Amresco). The re-suspended cells were disrupted by gentle sonication on ice ( $5 \mathrm{~s}$ pulse of sonication with $10 \mathrm{~s}$ intervals for $12 \mathrm{~min}$ ) and centrifuged at $20,000 \mathrm{~g}$ for $30 \mathrm{~min}$ at $4^{\circ} \mathrm{C}$. The pellet was discarded and the supernatant was centrifuged at 200,000 $\mathrm{g}$ for 60 min to obtain the membrane fraction. The membrane fraction was washed twice and finally re-suspended in solubilization buffer (50 mM NaCl, $50 \mathrm{mM}$ Imidazole/ $\mathrm{HCl}, 2 \mathrm{mM}$ 6-Aminohexanoic acid (ACA), $1 \mathrm{mM}$ EDTA, pH 7.0) and further treated for $\mathrm{BN}$ gel or stored at $-80^{\circ} \mathrm{C}$. Protein concentration was determined using the Bradford assay [65].

Protein complexes were solubilized at $4{ }^{\circ} \mathrm{C}$ in solubilization buffer containing varying amounts of detergents. Triton X-100, DDM, Sulfobetaine SB10 and 3-[(3-cholamidopropyl) dimethylamonio]-1-propanesulfonate (Chaps) at concentrations ranging from $0.5 \%$ to $2.0 \%$ $(\mathrm{w} / \mathrm{v})$ were tested. Solubilization with $1.0 \%(\mathrm{w} / \mathrm{v}) \mathrm{DDM}$ was found to be most effective, as evidenced by the number of complexes in the BN gel, the intensity and the molecular mass range of these complexes. Subsequent experiments were therefore performed using $1.0 \%$ (w/v) DDM as detergent. Following solubilization, samples were cleared by centrifugation at 200,000 g for 30 min at $4^{\circ} \mathrm{C}$. The supernatant was mixed with $15 \mu \mathrm{l}$ of G250 solution (5\% (w/v) SERVA Blue G (SERVA Electrophoresis $\mathrm{GmbH}$ ) in $500 \mathrm{mM}$ ACA buffer) and loaded onto the $\mathrm{BN}$ gel.

\section{Two dimensional BN/SDS PAGE}

BN-PAGE and SDS-PAGE were performed using a DYY-23A apparatus (product of Beijing WoDeLife Sciences Instrument Company). In the first dimensional BN-PAGE, approximately $40 \mu \mathrm{g}$ of protein was loaded. A $3.5 \%$ stacking and a $4-15 \%$ separating gel (gel dimensions $10 \mathrm{~cm} \times 10 \mathrm{~cm} \times 1.5 \mathrm{~mm}$ ) were used. Buffers and gel compositions used were the same as described by Wittig et al [66]. Electrophoresis was conducted at $100 \mathrm{~V}$ for $30 \mathrm{~min}$, and following electrophoresis was performed with the current limited to $15 \mathrm{~mA}$ and voltage limited to $300 \mathrm{~V}$. Ferritin, catalase and BSA from Amersham Biosciences (Sweden) were used as markers to indicate the sizes of 880, 440, 250, 132 and $66 \mathrm{kDa}$. BN-polyacrylamide gel strips were cut from the first dementional gel for use in the second dimensional SDS-PAGE.

For the second dimensional SDS-PAGE, strips of the first dimensional BN-PAGE were cut and soaked in 5\% (w/v) SDS, 1\% (w/v) 2-Mercaptoethanol for 2 h. SDSPAGEs were performed using a $4 \%$ stacking and a $12 \%$ separating gel according to standard protocols. Gels were fixed in $50 \%(\mathrm{v} / \mathrm{v})$ methanol and $12 \%(\mathrm{v} / \mathrm{v})$ acetic acid for 1 hour and then stained with $0.25 \%(\mathrm{w} / \mathrm{v})$ Coomassie Blue R250 in 10\% (v/v) acetic acid and 50\% (v/v) methanol. A series of proteins (Tiangen Company, China) with the sizes of 116, 66.2, 45, 35, 25, 18.4 and 14.4 $\mathrm{kDa}$ were used as markers.

\section{MALDI-TOF MS and MS/MS}

Protein spots from SDS gel were excised manually. Ingel trypsin digestion was carried out as previously described [67]. A $0.4 \mu \mathrm{l}$ aliquot of the concentrated tryptic peptide mixture in $0.1 \%$ trifluoroacetic acid (TFA) was mixed with $0.4 \mu$ l of $\alpha$-cyano-4-hydroxycinnamic acid (CHCA) matrix solution $(5 \mathrm{mg} / \mathrm{ml} \mathrm{CHCA} \mathrm{in} 50 \%$ ACN/0.1\% TFA) and spotted onto a freshly cleaned target plate. After air drying, the crystallized spots were analyzed on the Applied Biosystems 4700 Proteomics Analyzer MALDI-TOF/TOF (Applied Biosystems, Framingham, MA, USA). MS calibration was automatically performed by a peptide standard Kit (Applied Biosystems) containing des-Arg1-bradykinin (m/z 904), Angiotensin I (m/z 1296.6851), Glu1-fibrinopeptide B (m/z 1570.6774), Adrenocorticotropic hormone (ACTH) (117, m/z 2903.0867), ACTH (18-39, m/z 2465.1989), and ACTH (7-38, m/z 3657.9294) and MS/MS calibration was performed by the MS/MS fragment peaks of Glu1fibrinopeptide B. All MS mass spectra were recorded in the reflector positive mode using a laser operated at a $200 \mathrm{~Hz}$ repetition rate with wavelength of $355 \mathrm{~nm}$. The accelerated voltage was operated at $2 \mathrm{kV}$. The MS/MS mass spectra were acquired by the data dependent acquisition method with the 10 strongest precursors selected from one MS scan. All MS and MS/MS spectra were obtained by accumulation of at least 1000 and 3000 laser shots, respectively. Neither baseline subtraction nor smoothing was applied to recorded spectra. MS and MS/MS data were analyzed and peak lists were generated using GPS Explorer 3.5 (Applied Biosystems). MS peaks were selected between 700 and $3500 \mathrm{Da}$ and filtered with a signal to noise ratio greater than 20 . 
A peak intensity filter was used with no more than 50 peaks per $200 \mathrm{Da}$. MS/MS peaks were selected based on a signal to noise ratio greater than 10 over a mass range of $60 \mathrm{Da}$ to $20 \mathrm{Da}$ below the precursor mass. MS and MS/MS data were analyzed using MASCOT ${ }^{\mathrm{TM}}$ 2.0 search engine (Matrix Science, London, UK) to search against the $C$. themocellum protein sequence database downloaded from NCBI database on December 01 2008. Searching parameters were as follows: trypsin digestion with one missed cleavage, variable modifications (oxidation of methionine and carbamidomethylation of cysteine), and the mass tolerance of precursor ion and fragment ion at $0.2 \mathrm{Da}$ for +1 charged ions. For all proteins successfully identified by Peptide Mass Fingerprint and/or MS/MS, Mascot score greater than 53 (the default MASCOT threshold for such searches) was accepted as significant ( $p$ value $<$ $0.05)$. The false positive rate was estimated based on reverse database search. The false positive rate $=$ peptide fragment numbers detected in reverse database search/(peptide fragment numbers in forward database search+ peptide fragment numbers in reverse database search) $\times 100 \%$.

\section{Additional material}

Additional file 1: Results of ATPase search in published genomes of eubacteria from NCBI. Table listing the eubacteria which contain F-type ATPase, V-type ATPase or both F-type and V-type ATPases.

\section{Acknowledgements}

The authors wish to acknowledge the kind assistance of Dr. Xiu-yun Tian for electrophoresis during the course of this study. This work is supported by Ministry of Science and Technology of China, Grant 2007CB707800.

\section{Author details \\ 'State Key Laboratory of Microbial Resources, Institute of Microbiology, Chinese Academy of Sciences, Beijing 100101, PR China. ${ }^{2}$ Department of physiology and Biophysics, School of Medicine, Virginia Commonwealth University, 1101 East Marshall Street, Richmond, VA 23298, USA.}

\section{Authors' contributions \\ YP performed all experiments and wrote the manuscript. YL performed the MALDI-TOF and wrote the MALDI-TOF MS and MS/MS part of the manuscript. TY and KF were involved in study design and revising the manuscript. YZ performed the database search of ATPase in bacteria. KY supervised the project and revised the manuscript. All authors read and approved the final manuscript.}

Received: 25 October 2010 Accepted: 26 January 2011

Published: 26 January 2011

\section{References}

1. Demain AL, Newcomb M, Wu JH: Cellulase, clostridia, and ethanol. Microbiol Mol Biol Rev 2005, 69(1):124-154.

2. Roberts SB, Gowen CM, Brooks JP, Fong SS: Genome-scale metabolic analysis of Clostridium thermocellum for bioethanol production. BMC Syst Biol 2010, 4(31)

3. Alberts B: The cell as a collection of protein machines: preparing the next generation of molecular biologists. Cell 1998, 92(3):291-294.
4. Schagger $\mathrm{H}$, von Jagow $\mathrm{G}$ : Blue native electrophoresis for isolation of membrane protein complexes in enzymatically active form. Anal Biochem 1991, 199(2):223-231.

5. Stroh A, Anderka O, Pfeiffer K, Yagi T, Finel M, Ludwig B, Schagger H: Assembly of respiratory complexes I, III, and IV into NADH oxidase supercomplex stabilizes complex I in Paracoccus denitrificans. J Biol Chem 2004, 279(6):5000-5007.

6. Cruciat CM, Brunner S, Baumann F, Neupert W, Stuart RA: The cytochrome bc1 and cytochrome c oxidase complexes associate to form a single supracomplex in yeast mitochondria. J Biol Chem 2000, 275(24):18093-18098.

7. Ciambella C, Roepstorff P, Aro EM, Zolla L: A proteomic approach for investigation of photosynthetic apparatus in plants. Proteomics 2005, 5(3):746-757.

8. Herranen M, Battchikova N, Zhang P, Graf A, Sirpio S, Paakkarinen V, Aro EM: Towards functional proteomics of membrane protein complexes in Synechocystis sp. PCC 6803. Plant Physiol 2004, 134(1):470-481.

9. Pan JY, Li H, Ma Y, Chen P, Zhao P, Wang SY, Peng XX: Complexome of Escherichia coli envelope proteins under normal physiological conditions. J Proteome Res 2010, 9(7):3730-3740.

10. Stenberg F, Chovanec P, Maslen SL, Robinson CV, llag LL, von Heijne G, Daley DO: Protein complexes of the Escherichia coli cell envelope. J Biol Chem 2005, 280(41):34409-34419.

11. Krogh A, Larsson B, von Heijne G, Sonnhammer EL: Predicting transmembrane protein topology with a hidden Markov model: application to complete genomes. J Mol Biol 2001, 305(3):567-580.

12. Sonnhammer EL, von Heijne G, Krogh A: A hidden Markov model for predicting transmembrane helices in protein sequences. Proc Int Conf Intell Syst Mol Biol 1998, 6:175-182.

13. Tatusov RL, Natale DA, Garkavtsev IV, Tatusova TA, Shankavaram UT, Rao BS, Kiryutin B, Galperin MY, Fedorova ND, Koonin EV: The COG database: new developments in phylogenetic classification of proteins from complete genomes. Nucleic Acids Res 2001, 29(1):22-28.

14. Tatusov RL, Galperin MY, Natale DA, Koonin EV: The COG database: a tool for genome-scale analysis of protein functions and evolution. Nucleic Acids Res 2000, 28(1):33-36

15. Lee LK, Stewart AG, Donohoe M, Bernal RA, Stock D: The structure of the peripheral stalk of Thermus thermophilus $\mathrm{H}(+)$-ATPase/synthase. Nat Struct Mol Biol 2010, 17(3):373-378.

16. Capaldi RA, Aggeler R: Mechanism of the F(1)F(0)-type ATP synthase, a biological rotary motor. Trends Biochem Sci 2002, 27(3):154-160.

17. Yokoyama K, Imamura $\mathrm{H}$ : Rotation, structure, and classification of prokaryotic V-ATPase. J Bioenerg Biomembr 2005, 37(6):405-410.

18. Takase $K$, Yamato I, Kakinuma Y: Cloning and sequencing of the genes coding for the $A$ and $B$ subunits of vacuolar-type $\mathrm{Na}(+)$-ATPase from Enterococcus hirae. Coexistence of vacuolar- and FOF1-type ATPases in one bacterial cell. J Biol Chem 1993, 268(16):11610-11616.

19. Murata T, Yamato I, Kakinuma Y, Leslie AG, Walker JE: Structure of the rotor of the V-Type Na+-ATPase from Enterococcus hirae. Science 2005, 308(5722):654-659.

20. Murata T, Kawano M, Igarashi K, Yamato I, Kakinuma Y: Catalytic properties of $\mathrm{Na}(+)$-translocating V-ATPase in Enterococcus hirae. Biochim Biophys Acta 2001, 1505(1):75-81.

21. Honer zu Bentrup K, Ubbink-Kok T, Lolkema JS, Konings WN: An Na +-pumping V1V0-ATPase complex in the thermophilic bacterium Clostridium fervidus. J Bacteriol 1997, 179(4):1274-1279.

22. Reid MF, Fewson CA: Molecular characterization of microbial alcohol dehydrogenases. Crit Rev Microbiol 1994, 20(1):13-56.

23. Espinosa A, Yan L, Zhang Z, Foster L, Clark D, Li E, Stanley SL Jr: The bifunctional Entamoeba histolytica alcohol dehydrogenase 2 (EhADH2) protein is necessary for amebic growth and survival and requires an intact C-terminal domain for both alcohol dahydrogenase and acetaldehyde dehydrogenase activity. J Biol Chem 2001, 276(23):20136-20143.

24. Habe H, Fukuoka T, Morita T, Kitamoto D, Yakushi T, Matsushita K, Sakaki K Disruption of the Membrane-Bound Alcohol Dehydrogenase-Encoding Gene Improved Glycerol Use and Dihydroxyacetone Productivity in Gluconobacter oxydans. Biosci Biotechnol Biochem 2010.

25. Gomez-Manzo S, Solano-Peralta A, Saucedo-Vazquez JP, EscamillaMarvan JE, Kroneck PM, Sosa-Torres ME: The membrane-bound quinohemoprotein alcohol dehydrogenase from Gluconacetobacter 
diazotrophicus PAL5 carries a [2Fe-2S] cluster. Biochemistry 2010 49(11):2409-2415.

26. Moonmangmee D, Fujii $Y$, Toyama $H$, Theeragool G, Lotong $N$, Matsushita K, Adachi O: Purification and characterization of membranebound quinoprotein cyclic alcohol dehydrogenase from Gluconobacter frateurii CHM 9. Biosci Biotechnol Biochem 2001, 65(12):2763-2772.

27. Choi-Rhee E, Cronan JE: The biotin carboxylase-biotin carboxyl carrier protein complex of Escherichia coli acetyl-CoA carboxylase. J Biol Chem 2003, 278(33):30806-30812.

28. Cronan JE Jr, Waldrop GL: Multi-subunit acetyl-CoA carboxylases. Prog Lipid Res 2002, 41(5):407-435.

29. Diacovich L, Peiru S, Kurth D, Rodriguez E, Podesta F, Khosla C, Gramajo H: Kinetic and structural analysis of a new group of Acyl-CoA carboxylases found in Streptomyces coelicolor A3(2). J Biol Chem 2002, 277(34):31228-31236.

30. Hugler M, Krieger RS, Jahn M, Fuchs G: Characterization of acetyl-CoA/ propionyl-CoA carboxylase in Metallosphaera sedula. Carboxylating enzyme in the 3-hydroxypropionate cycle for autotrophic carbon fixation. Eur J Biochem 2003, 270(4):736-744.

31. Santoro N, Brtva T, Roest SV, Siegel K, Waldrop GL: A high-throughput screening assay for the carboxyltransferase subunit of acetyl-CoA carboxylase. Anal Biochem 2006, 354(1):70-77.

32. Finlayson SA, Dennis DT: Acetyl-coenzyme A carboxylase from the developing endosperm of Ricinus communis. I. Isolation and characterization. Arch Biochem Biophys 1983, 225(2):576-585.

33. Feldman-Salit A, Wirtz M, Hell R, Wade RC: A Mechanistic Model of the Cysteine Synthase Complex. J Mol Biol 2009, 386(1):37-59.

34. Jurgenson CT, Burns KE, Begley TP, Ealick SE: Crystal structure of a sulfur carrier protein complex found in the cysteine biosynthetic pathway of Mycobacterium tuberculosis. Biochemistry 2008, 47(39):10354-10364.

35. Huang CZ, Lin XM, Wu LN, Zhang DF, Liu D, Wang SY, Peng XX: Systematic identification of the subproteome of Escherichia coli cell envelope reveals the interaction network of membrane proteins and membraneassociated peripheral proteins. J Proteome Res 2006, 5(12):3268-3276.

36. de Las Rivas B, Fox GC, Angulo I, Ripoll MM, Rodriguez H, Munoz R, Mancheno JM: Crystal structure of the hexameric catabolic ornithine transcarbamylase from Lactobacillus hilgardii: Structural insights into the oligomeric assembly and metal binding. J Mol Biol 2009, 393(2):425-434.

37. Shi D, Morizono H, Aoyagi M, Tuchman M, Allewell NM: Crystal structure of human ornithine transcarbamylase complexed with carbamoyl phosphate and L-norvaline at 1.9 A resolution. Proteins 2000, 39(4):271-277.

38. Villeret V, Clantin B, Tricot C, Legrain C, Roovers M, Stalon V, Glansdorff N, Van Beeumen J: The crystal structure of Pyrococcus furiosus ornithine carbamoyltransferase reveals a key role for oligomerization in enzyme stability at extremely high temperatures. Proc Natl Acad Sci USA 1998, 95(6):2801-2806.

39. Tricot C, Villeret V, Sainz G, Dideberg O, Stalon V: Allosteric regulation in Pseudomonas aeruginosa catabolic ornithine carbamoyltransferase revisited: association of concerted homotropic cooperative interactions and local heterotropic effects. J Mol Biol 1998, 283(3):695-704.

40. Alam SI, Bansod S, Kumar RB, Sengupta N, Singh L: Differential proteomic analysis of Clostridium perfringens ATCC13124; identification of dominant, surface and structure associated proteins. BMC Microbiol 2009, 9:162

41. Hughes MJ, Moore JC, Lane JD, Wilson R, Pribul PK, Younes ZN, Dobson RJ, Everest $P$, Reason AJ, Redfern JM, et al: Identification of major outer surface proteins of Streptococcus agalactiae. Infect Immun 2002, 70(3):1254-1259.

42. Shi D, Morizono H, Ha Y, Aoyagi M, Tuchman M, Allewell NM: 1.85-A resolution crystal structure of human ornithine transcarbamoylase complexed with N-phosphonacetyl-L-ornithine. Catalytic mechanism and correlation with inherited deficiency. J Biol Chem 1998, 273(51):34247-34254.

43. Saikawa N, Akiyama Y, Ito K: FtsH exists as an exceptionally large complex containing HfIKC in the plasma membrane of Escherichia coli. I Struct Biol 2004, 146(1-2):123-129.
44. Narberhaus F, Obrist M, Fuhrer F, Langklotz S: Degradation of cytoplasmic substrates by $\mathrm{FtsH}$, a membrane-anchored protease with many talents. Res Microbiol 2009, 160(9):652-659.

45. Niwa H, Tsuchiya D, Makyio H, Yoshida M, Morikawa K: Hexameric ring structure of the ATPase domain of the membrane-integrated metalloprotease FtsH from Thermus thermophilus HB8. Structure 2002, 10(10): 1415-1423.

46. Nurmohamed S, Vaidialingam B, Callaghan AJ, Luisi BF: Crystal structure of Escherichia coli polynucleotide phosphorylase core bound to RNase $E_{\text {, }}$ RNA and manganese: implications for catalytic mechanism and RNA degradosome assembly. J Mol Biol 2009, 389(1):17-33.

47. Chen HW, Koehler CM, Teitell MA: Human polynucleotide phosphorylase: location matters. Trends Cell Biol 2007, 17(12):600-608.

48. Briani F, Del Favero M, Capizzuto R, Consonni C, Zangrossi S, Greco C, De Gioia L, Tortora P, Deho G: Genetic analysis of polynucleotide phosphorylase structure and functions. Biochimie 2007, 89(1):145-157.

49. Lorentzen E, Walter P, Fribourg S, Evguenieva-Hackenberg E, Klug G, Conti $\mathrm{E}$ : The archaeal exosome core is a hexameric ring structure with three catalytic subunits. Nat Struct Mol Biol 2005, 12(7):575-581.

50. Symmons MF, Jones GH, Luisi BF: A duplicated fold is the structural basis for polynucleotide phosphorylase catalytic activity, processivity, and regulation. Structure 2000, 8(11):1215-1226.

51. Taghbalout $A$, Rothfield $L:$ New insights into the cellular organization of the RNA processing and degradation machinery of Escherichia coli. Mol Microbiol 2008, 70(4):780-782.

52. Owen P, Kaback HR: Immunochemical analysis of membrane vesicles from Escherichia coli. Biochemistry 1979, 18(8):1413-1422.

53. Tatur J, Hagen WR, Matias PM: Crystal structure of the ferritin from the hyperthermophilic archaeal anaerobe Pyrococcus furiosus. J Biol Inorg Chem 2007, 12(5):615-630.

54. Carrondo MA: Ferritins, iron uptake and storage from the bacterioferritin viewpoint. EMBO J 2003, 22(9):1959-1968.

55. Davidson AL, Dassa E, Orelle C, Chen J: Structure, function, and evolution of bacterial ATP-binding cassette systems. Microbiol Mol Biol Rev 2008, 72(2):317-364, table of contents.

56. Hvorup RN, Goetz BA, Niederer M, Hollenstein K, Perozo E, Locher KP: Asymmetry in the structure of the $A B C$ transporterbinding protein complex BtuCD-BtuF. Science 2007, 317(5843):1387-1390.

57. Hollenstein K, Frei DC, Locher KP: Structure of an $A B C$ transporter in complex with its binding protein. Nature 2007, 446(7132):213-216.

58. Nataf $Y$, Yaron $S$, Stahl F, Lamed R, Bayer EA, Scheper TH, Sonenshein AL, Shoham Y: Cellodextrin and laminaribiose $A B C$ transporters in Clostridium thermocellum. J Bacteriol 2009, 191(1):203-209.

59. Ferner-Ortner J, Mader C, IIk N, Sleytr UB, Egelseer EM: High-affinity interaction between the S-layer protein SbsC and the secondary cell wall polymer of Geobacillus stearothermophilus ATCC 12980 determined by surface plasmon resonance technology. J Bacteriol 2007, 189(19):7154-7158.

60. Mader C, Huber C, Moll D, Sleytr UB, Sara M: Interaction of the crystalline bacterial cell surface layer protein SbsB and the secondary cell wall polymer of Geobacillus stearothermophilus PV72 assessed by real-time surface plasmon resonance biosensor technology. J Bacteriol 2004, 186(6):1758-1768.

61. Mesnage S, Fontaine T, Mignot T, Delepierre M, Mock M, Fouet A: Bacterial $\mathrm{SLH}$ domain proteins are non-covalently anchored to the cell surface via a conserved mechanism involving wall polysaccharide pyruvylation. EMBO J 2000, 19(17):4473-4484.

62. Helaine $\mathrm{S}$, Dyer DH, Nassif $\mathrm{X}$, Pelicic $\mathrm{V}$, Forest $\mathrm{KT}$ : 3D structure/function analysis of PilX reveals how minor pilins can modulate the virulence properties of type IV pili. Proc Natl Acad Sci USA 2007, 104(40):15888-15893.

63. Williams TI, Combs JC, Thakur AP, Strobel HJ, Lynn BC: A novel Bicine running buffer system for doubled sodium dodecyl sulfate polyacrylamide gel electrophoresis of membrane proteins. Electrophoresis 2006, 27(14):2984-2995. 
64. Williams TI, Combs JC, Lynn BC, Strobel HJ: Proteomic profile changes in membranes of ethanol-tolerant Clostridium thermocellum. Appl Microbiol Biotechnol 2007, 74(2):422-432.

65. Bradford MM: A rapid and sensitive method for the quantitation of microgram quantities of protein utilizing the principle of protein-dye binding. Anal Biochem 1976, 72:248-254.

66. Wittig I, Braun HP, Schagger H: Blue native PAGE. Nat Protoc 2006, 1(1):418-428.

67. Fernandez-Arenas E, Cabezon V, Bermejo C, Arroyo J, Nombela C, DiezOrejas R, Gil C: Integrated proteomics and genomics strategies bring new insight into Candida albicans response upon macrophage interaction. Mol Cell Proteomics 2007, 6(3):460-478.

doi:10.1186/1471-2180-11-22

Cite this article as: Peng et al.: A Blue Native-PAGE analysis of membrane protein complexes in Clostridium thermocellum. BMC Microbiology 2011 11:22.

Submit your next manuscript to BioMed Central and take full advantage of:

- Convenient online submission

- Thorough peer review

- No space constraints or color figure charges

- Immediate publication on acceptance

- Inclusion in PubMed, CAS, Scopus and Google Scholar

- Research which is freely available for redistribution

Submit your manuscript at www.biomedcentral.com/submit 